\section{Doubled Haploid Onion (Allium cepa L.) Lines and Their Impact on Hybrid Performance}

\author{
Peter T. Hyde, Elizabeth D. Earle, and Martha A. Mutschler ${ }^{1}$ \\ Department of Plant Breeding and Genetics, Cornell University, 303 \\ Bradfield Hall, Ithaca, NY 14583
}

Additional index words. heterosis, hybrid vigor, inbred line development, gynogenesis

\begin{abstract}
Production of double haploid (DH) lines is a rapid method of obtaining completely homozygous inbred lines for numerous crops; however, practical trials testing the use of DH onion lines have been limited. DH onion lines were produced from diverse highly heterozygous material in development within the Cornell onion breeding program. These DH lines were evaluated in multiple replicated trials in onion fields in New York as lines and as parents of hybrids to assess the impact and commercial potential of DH onions. Twenty DH onion lines were compared with open-pollinated cultivars developed from the same source germplasm and with a commercial hybrid over two years. The vegetative vigor of the DH lines was comparable to that of related openpollinated cultivars, showing minimal, if any, inbreeding depression. Two sets of hybrids were produced using the DH lines as males and two different females that are the female parents of the commercial hybrid controls. Therefore, hybrids in each set are half-sibs, and any performance differences are attributable to their DH male lines. In four replicated trials of these hybrids and controls, the experimental hybrids were either not significantly different or significantly better in measures of vegetative vigor compared with conventional half-sib hybrid controls. The vegetative vigor of $\mathrm{DH}$ lines, and their derived hybrids, might result from selection of plantlets without deleterious sublethal genes during gynogenesis. The shortened development time and equivalent quality of DH lines compared with the traditionally bred onion inbreds warrant their use. The increased vigor in hybrid combination could be an additional benefit for onion breeding strategies.
\end{abstract}

Breeding of dry storage onion for the last 60 years largely focused on production of inbred lines for creation of hybrid varieties after Jones and Clarke (1943) and Jones and Davis (1944) outlined how the cytoplasmic male sterility system could be used for largescale production of hybrid seed. Hybrids were rapidly adopted by growers as a result of their significant increase in marketable yield as well as greater uniformity for horticultural traits compared with standard open-pollinated onion varieties (Dowker and Gordon, 1983; Evoor et al., 2007; Hosfield et al., 1977; Joshi and Tandon, 1976).

Received for publication 9 July 2012. Accepted for publication 23 Oct. 2012.

Funding for this project was provided in part by Hatch project NYC-149489 and by seed company donations through the Vegetable Breeding Institute.

We thank Bejo Seed Co. for use of proprietary male-sterile lines and technical assistance for marker analysis, seed production, and the Bejo staff at Geneva New York for assistance with the Oswego, NY, trial. We also thank Drs. Michael Havey and David Wolfe for providing critical reviews of this manuscript. Additionally, we are greatly appreciative for the assistance given by Cornell statisticians Francoise Vermeylen and Jay Barry while planning and analyzing the data from this experiment.

${ }^{1}$ To whom reprint requests should be addressed; e-mailmam13@cornell.edu. selection practices to develop inbred lines using the single-seed descent method takes 10 to 12 years (Bohanec, 2002).

DH lines have been used to accelerate inbred line development in commercial breeding programs of various crops, including rice, maize, rapeseed, tobacco, and barley, as a result of the rapid production time and superior uniformity compared with conventionally bred inbred lines (Bong and Swaminathan, 1995; Maluszynski et al., 2003; Röber et al., 2005). DH plants can be produced in vitro by generating plantlets from gynogenic or androgenic haploid cells. These haploid plantlets either spontaneously double their chromosomes or are chemically stimulated to do so, creating DH plants that are completely homozygous (Maluszynski et al., 2003). Development of homozygous $\mathrm{DH}$ onion lines can be much quicker and more cost-effective than conventional breeding procedures (Alan et al., 2003, 2004; Bohanec, 2002).

A series of $\mathrm{DH}$ onion lines was produced from diverse, highly heterozygous material in development within the Cornell onion breeding program (Alan et al., 2003, 2004). The objectives of the current study were to evaluate these DH lines individually and to assess their use as males in hybrid combinations in terms of vegetative vigor, bulb quality, and uniformity of horticultural traits for their potential in commercial onion production.

\section{Material and Methods}

Plant material. DH lines were created through gynogenesis (Alan et al., 2003, 2004) using flowers collected from plants of populations in the Cornell onion breeding program that ultimately produced the open-pollinated cultivars YIX $\mathrm{C}$ and YIX E using conventional breeding methods. The initial YIX population was created by intermating the six inbred lines, MSU5718, NY53E-21, NY1541, NY63-26, MSU8155, and NY72-4. The resulting extremely heterogeneous progeny were selected and selfed for two generations. Subpopulations SYN-YIX C and SYN-YIX $\mathrm{E}$ were identified and underwent two cycles of mass selection for bulb type before the flowers were selected for use in gynogenesis. SYN-YIX C and SYN-YIX E underwent three more cycles of mass selection before the open-pollinated cultivars YIX C and YIX $\mathrm{E}$ were created. Four DH onion lines were derived from SYN-YIX C, and $16 \mathrm{DH}$ onion lines were derived from SYN-YIX E (Alan et al., 2003, 2004). Subsets of this set of DH lines were used for direct line trials. The controls for the line trials were the commercial hybrid Festival (Bejo Zaden B.V., Warmenhuizen, The Netherlands) as well as the related cultivars YIX C and YIX E, described previously.

DH hybrids were produced by using DH lines described previously as male parents on one or both of two Bejo (Bejo Zaden B.V.) proprietary female (male-cytosterile) A lines. In preparation for these crosses, eight bulbs from each $\mathrm{DH}$ line lot were tested for uniformity and homozygosity by Bejo using five 
proprietary polymerase chain reaction-based markers. The $16 \mathrm{DH}$ lines used for hybrid seed production and evaluation were uniform for band pattern among plants within a DH line. One of the female lines was an American long-storage pungent onion typical of northeast pungent long-day onions; it is referred to as "Am-type." Sixteen of the experimental DH hybrids were produced using this Am-type female, which is also the female parent of the pungent storage commercial onion hybrids Safrane and Crockett (Bejo Zaden B.V.). Thus, the 16 experimental hybrids, Safrane, and Crockett are all half-sibs. The other female line used was an American Spanish-style onion line; it is referred to as "AmSp-type." Nine of the experimental DH hybrids were produced using this AmSp-type female, which is also the female parent of the American Spanish-type commercial onion control hybrids Medeo and Calibra (Bejo Zaden B.V.). Thus, the nine experimental hybrids, Medeo, and Calibra are all half-sibs.

Seed treatment. Seeds for direct-sown trials in 2008 and 2009 were treated before sowing to control onion maggot (Delia antiqua) and onion smut (Urocystis cepulae). The seeds were coated with tebuconazole (Raxcil 2.6 F; Bayer AG, Leverkusen, Germany) $250 \mathrm{mg} /$ $100 \mathrm{~g}$ seed, thiram (Thiram $42 \mathrm{~S}$; Bayer AG) $188 \mathrm{mg} / 100 \mathrm{~g}$ seed, fipronil (Mundial; BASF, Florham Park, NJ) $2.5 \mathrm{~g} / 100 \mathrm{~g}$ seed, and the binding agent DISCO (Incotec, Salinas, CA) at a 1:1 ratio with control agents. This mixture was applied at $150 \mu \mathrm{L}$ per 250 seeds, and then seeds were air-dried.

Doubled haploid line trial in 2006. Nineteen of the DH onion lines were tested in 2006 using the related cultivars YIX C and YIX E as controls along with the commercial hybrid Festival (Table 1). Seedlings were greenhouse grown to $\approx 7$ weeks old in 288-cell plug trays filled with Cornell mix (Boodley and Sheldrake, 1972), hardened off several days in coldframes, and transplanted in mineral soil plots at the Cornell East Ithaca research farm. Seedlings were planted at 7.6- $\mathrm{cm}$ spacing within row with $30.5 \mathrm{~cm}$ between rows. Each genotype was planted in four 18-plant replications in a completely randomized block design.

Doubled haploid line and doubled haploid hybrid trials in 2008. The 2008 trial of DH lines was grown on muck soil in Elba, $\mathrm{NY}$, in a plot embedded within a commercial onion field. The trial consisted of $15 \mathrm{DH}$ lines and the control line Festival (Table 1) in a completely randomized block design with three replications. Each entry was represented by one $6.1-\mathrm{m}$ row directly sown with 200 seeds giving 200 seeds in each replicate. Each row was spaced $0.3 \mathrm{~m}$ apart with the seeds sown at $1.27-\mathrm{cm}$ depth.

The 2008 trial of DH hybrids was grown in Elba, NY, in a plot embedded within a commercial onion field. The trial consisted of $25 \mathrm{DH}$ hybrids and four controls including both the Am type and AmSp type in a completely randomized block design with four replications. Each genotype was represented by two 7.2-m rows. Each row was planted with 250 seeds evenly spaced giving a total of 500 seeds in each replicate. Each row was spaced $0.3 \mathrm{~m}$ apart with the seeds sown at $1.27-\mathrm{cm}$ depth.

Doubled haploid hybrid trials 2009. The $\mathrm{DH}$ hybrid trials were grown in Elba, NY, and Oswego, NY, in plots embedded within commercial onion fields. The Elba trial included four replications each of the Am-type DH hybrids, the AmSp-type DH hybrids, and their respective controls. The Oswego trial was the same as the Elba trial, except that it had three replications of the AmSp-type DH hybrids. In both trials, each entry was represented by two $6.1-\mathrm{m}$ rows with 200 seeds in each row for a total of 400 seeds per replicate in a completely randomized block design. Seed were planted at a $1.27-\mathrm{cm}$ depth and 0.3 -m spacing between rows.

Table 1. Doubled haploid (DH) lines and their use in line and hybrid trials.

\begin{tabular}{|c|c|c|c|c|c|c|c|}
\hline \multirow{2}{*}{$\begin{array}{l}\text { Doubled haploid } \\
\text { line }\end{array}$} & \multirow[b]{2}{*}{ Source } & \multicolumn{2}{|c|}{ DH line trials } & \multicolumn{4}{|c|}{ DH hybrid trials } \\
\hline & & 2006 lines & 2008 lines & $2008 \mathrm{Am}^{\mathrm{z}}$ & $2008 \mathrm{AmSp}^{\mathrm{y}}$ & $2009 \mathrm{Am}$ & $2009 \mathrm{AmSp}$ \\
\hline DHCU066600 & SYN-YIX E & $\mathrm{X}$ & $\mathrm{X}$ & $\mathrm{X}$ & $\mathrm{X}$ & $\mathrm{X}$ & $\mathrm{X}$ \\
\hline DHCU066601 & SYN-YIX E & $\mathrm{X}$ & $\mathrm{X}$ & $\mathrm{X}$ & $\mathrm{X}$ & $\mathrm{X}$ & $\mathrm{X}$ \\
\hline DHCU066604 & SYN-YIX E & $\mathrm{X}$ & $\mathrm{X}$ & $\mathrm{X}$ & $\mathrm{X}$ & $\mathrm{X}$ & $\mathrm{X}$ \\
\hline DHCU066607 & SYN-YIX E & $\mathrm{X}$ & & & & & \\
\hline DHCU066608 & SYN-YIX E & $\mathrm{X}$ & & & & & \\
\hline DHCU066613 & SYN-YIX E & $\mathrm{X}$ & & $\mathrm{X}$ & $\mathrm{X}$ & $\mathrm{X}$ & $\mathrm{X}$ \\
\hline DHCU066614 & SYN-YIX E & & $\mathrm{X}$ & $\mathrm{X}$ & $\mathrm{X}$ & & \\
\hline DHCU066615 & SYN-YIX E & $\mathrm{X}$ & $\mathrm{X}$ & $\mathrm{X}$ & $\mathrm{X}$ & $X$ & $\mathrm{X}$ \\
\hline DHCU066616 & SYN-YIX E & $\mathrm{X}$ & $\mathrm{X}$ & $\mathrm{X}$ & $\mathrm{X}$ & & \\
\hline DHCU066619 & SYN-YIX E & $\mathrm{X}$ & $\mathrm{X}$ & $\mathrm{X}$ & $\mathrm{X}$ & $\mathrm{X}$ & X \\
\hline DHCU066627 & SYN-YIX E & $\mathrm{X}$ & $\mathrm{X}$ & $\mathrm{X}$ & & $\mathrm{X}$ & \\
\hline DHCU066628 & SYN-YIX E & $\mathrm{X}$ & $\mathrm{X}$ & $\mathrm{X}$ & & & \\
\hline DHCU066630 & SYN-YIX E & $\mathrm{X}$ & $\mathrm{X}$ & $\mathrm{X}$ & & $\mathrm{X}$ & \\
\hline DHCU066634 & SYN-YIX E & $\mathrm{X}$ & $\mathrm{X}$ & $\mathrm{X}$ & & $\mathrm{X}$ & \\
\hline DHCU066635 & SYN-YIX E & $\mathrm{X}$ & $\mathrm{X}$ & $\mathrm{X}$ & & $\mathrm{X}$ & \\
\hline DHCU066637 & SYN-YIX E & $\mathrm{X}$ & $\mathrm{X}$ & $\mathrm{X}$ & & $\mathrm{X}$ & \\
\hline DHCU066612 & SYN-YIX C & $\mathrm{X}$ & & & & & \\
\hline DHCU066621 & SYN-YIX C & $\mathrm{X}$ & $\mathrm{X}$ & $\mathrm{X}$ & $\mathrm{X}$ & & \\
\hline DHCU066631 & SYN-YIX C & $\mathrm{X}$ & $\mathrm{X}$ & $\mathrm{X}$ & & $\mathrm{X}$ & \\
\hline DHCU066633 & SYN-YIX C & $\mathrm{X}$ & & & & & \\
\hline
\end{tabular}

${ }^{\mathrm{z}} \mathrm{Am}=$ in trial of entries that were of American pungent storage-type onion.

${ }^{\mathrm{y}} \mathrm{AmSp}=$ in trial of entries that were American Spanish-type onion.

Harvest and grading. For the field trials in all years, onions were manually pulled from the ground when $\approx 75 \%$ of the leaves in the trial had fallen over. The onions were laid in the field with their leaves covering the bulbs to dry for $\approx 2$ weeks. After the leaves had dried down, the onions were harvested by cutting off the dried leaves and placing all the onions from each entry into a 50-pound plastic mesh onion bag. The bags then were placed in wooden onion crates $1.2 \mathrm{~m}$ square $\times 1.0 \mathrm{~m}$ tall. These were covered to protect them from rain and left outside to cure for approximately one month.

Grading was conducted approximately one month after harvesting when onions had finished curing. During the first grading, rotten or damaged bulbs were removed and the marketable onions were tallied and weighed. All the marketable onions were re-bagged and put into on-farm commercial onion cold storage in large wooden crates until the second grading, 8 to 12 weeks later, depending on the year when they were visually assessed for quality traits including bulb uniformity, color, root growth, neck tightness, cleaning ability (the ease with which the dried outer scale can be removed), and firmness.

Data analysis. Grading data were used to generate values of mean row weight and mean bulb weight for analysis, both calculated excluding culled onions. A mixed model analysis of variance (ANOVA) test was conducted using the generalized linear modeling procedures of JMP ${ }^{\circledR}$ (SAS Institute Inc., Cary, NC) and adjusted for random variation resulting from replication and location. The ANOVA tests were followed by a Student's $t$ test using a Bonferroni corrected alpha to account for multiple comparisons of each experimental line to the control, however, not comparing between individual experimental lines. Therefore, when the calculated $P$ value comparing the control with a given line was less than the Bonferroni corrected alpha, this line was determined to be significantly different from the control.

\section{Results}

Mean bulb weight of doubled haploid lines in 2006. An evaluation of mean bulb weight was used to determine the yield potential in this trial, because the onions were transplanted at an even spacing, providing a uniform stand count. Eleven of $15 \mathrm{DH}$ lines derived from the source population SYNYIX E were not significantly different in mean bulb weight from the conventionally bred and related variety YIX E (Table 2). Eight of these $15 \mathrm{DH}$ lines were not significantly different from the commercial control Festival. Similarly, two of four DH lines derived from the source population SYNYIX $\mathrm{C}$ were not significantly different in mean bulb weight from the conventionally bred related variety YIX C. However, all of the DH lines derived from SYN-YIX C were significantly smaller than Festival.

Doubled haploid lines and doubled haploid hybrids in 2008 trials. Eight of 
$15 \mathrm{DH}$ lines were not significantly different in row weight than Festival, the commercial hybrid control. Row weight of line DHCU066631 was greater than that of Festival (Table 3). Seven of these $15 \mathrm{DH}$ lines were not significantly different in mean bulb weight than Festival, and the lines DHCU066631 and DHCU066628 were greater than Festival for mean bulb weight.

The 2008 DH hybrid summer trial experienced heavy rain, and sections of the field were periodically flooded. In addition, there were two hail events that sheared leaves off many of the onions in parts of the field, affecting larger bulbs the most, thus adding another element of variability. As a result of these poor field and growing conditions, analysis of the $\mathrm{DH}$ hybrid data from the 2008 trials was limited. No analysis of mean row weight or mean bulb weight was performed; however, four lines, DHCU066614, DHCU066616, DHCU066621, and DHCU066628, were selected to be removed as entries in later trials based on observation of these trials.

American Spanish-type hybrid trial in 2009. The two AmSp-type trials grew very similarly with the average stand counts in the Oswego site at $37 \mathrm{~m}$ and in the Elba site $36 \mathrm{~m}$. A Student's $t$ test showed no significant difference in stand counts between the two locations with a $P$ value of 0.4488 . Therefore, the data from these two trials were combined and analyzed together. One row of AmSp $\times$ DHCU066604 was removed from the data set because it had been

Table 2. Mean bulb weight of doubled haploid (DH) lines compared with related lines YIX E or YIX C and hybrid control Festival in 2006 mineral soil trial, Ithaca. NY.

\begin{tabular}{|c|c|c|c|c|c|}
\hline Pedigree & Type of entry & $\begin{array}{c}\text { Mean bulb } \\
\text { wt (g) }\end{array}$ & SE & $\begin{array}{l}P \text { value different } \\
\text { from source }\end{array}$ & $\begin{array}{l}P \text { value different } \\
\text { from Festival }\end{array}$ \\
\hline Festival & Commercial hybrid control & 276 & 13 & & \\
\hline YIX E & Cultivar related to $\mathrm{DH}$ lines & 236 & 27 & & \\
\hline DHCU066608 & DH line from SYN-YIX E & 233 & 29 & $0.9213^{z}$ & 0.0923 \\
\hline DHCU066628 & DH line from SYN-YIX E & 230 & 13 & 0.8229 & 0.0358 \\
\hline DHCU066615 & DH line from SYN-YIX E & 228 & 25 & 0.7638 & 0.0608 \\
\hline DHCU066604 & DH line from SYN-YIX E & 217 & 27 & 0.4720 & 0.0235 \\
\hline DHCU066627 & DH line from SYN-YIX E & 211 & 24 & 0.3379 & 0.0129 \\
\hline DHCU066635 & DH line from SYN-YIX E & 210 & 12 & 0.3090 & 0.0111 \\
\hline DHCU066630 & DH line from SYN-YIX E & 208 & 19 & 0.2709 & 0.0089 \\
\hline DHCU066616 & DH line from SYN-YIX E & 200 & 18 & 0.1635 & 0.0040 \\
\hline DHCU066634 & DH line from SYN-YIX E & 196 & 20 & 0.1205 & $0.0025 *$ \\
\hline DHCU066619 & DH line from SYN-YIX E & 185 & 17 & 0.0449 & $0.0005^{*}$ \\
\hline DHCU066601 & DH line from SYN-YIX E & 168 & 21 & 0.0101 & $0.0001 *$ \\
\hline DHCU066613 & DH line from SYN-YIX E & 145 & 5 & $0.0005^{* \mathrm{x}}$ & $0.0001 *$ \\
\hline DHCU066600 & DH line from SYN-YIX E & 143 & 30 & $0.0007 *$ & $0.0001 *$ \\
\hline DHCU066637 & DH line from SYN-YIX E & 135 & 9 & $0.0002 *$ & $0.0001 *$ \\
\hline DHCU066607 & DH line from SYN-YIX E & 125 & 6 & $0.0001^{*}$ & $0.0001 *$ \\
\hline Festival & Commercial hybrid control & 276 & 13 & & \\
\hline YIX C & Cultivar related to $\mathrm{DH}$ lines & 266 & 12 & & \\
\hline DHCU066631 & DH line from SYN-YIX C & 223 & 13 & $0.0267^{y}$ & $0.0083 *$ \\
\hline DHCU066612 & DH line from SYN-YIX C & 222 & 19 & 0.0258 & $0.0080 *$ \\
\hline DHCU066633 & DH line from SYN-YIX C & 136 & 15 & $0.0001 *$ & $0.0001 *$ \\
\hline DHCU066621 & DH line from SYN-YIX C & 107 & 7 & $0.0001 *$ & $0.0001 *$ \\
\hline
\end{tabular}

${ }^{\mathrm{z} F o r ~ Y I X ~ E-d e r i v e d ~ D H ~ l i n e s, ~ B o n f e r r o n i ~ c o r r e c t e d ~ a l p h a ~ f o r ~} 15$ comparisons 0.0033 .

${ }^{\mathrm{y}}$ For YIX C-derived DH lines, Bonferroni corrected alpha for four comparisons 0.0125 .

$\mathrm{x} *$ indicates $95 \%$ confidence of a significant difference from the source line or Festival.

Table 3. Mean row weight and mean bulb weight of doubled haploid (DH) lines grown in commercial muck field in 2008 compared with the control hybrid Festival.

\begin{tabular}{lcccccc}
\hline Pedigree & $\begin{array}{c}\text { Mean row } \\
\text { wt }(\mathrm{kg})\end{array}$ & SE & $\begin{array}{c}P \text { value different } \\
\text { from Festival }\end{array}$ & $\begin{array}{c}\text { Mean bulb } \\
\text { wt }(\mathrm{g})\end{array}$ & $\begin{array}{c}P \text { value different } \\
\text { from Festival }\end{array}$ \\
\hline DHCU066631 & 14.4 & 1.2 & $0.3781^{z}$ & 102 & 5 & 0.8038 \\
Festival & 12.9 & 1.3 & & 99 & 6 & 0.9862 \\
DHCU066630 & 12.5 & 1.2 & 0.7890 & 99 & 5 & 0.7180 \\
DHCU066619 & 12.3 & 1.2 & 0.7172 & 97 & 5 & 0.0277 \\
DHCU066627 & 11.1 & 1.2 & 0.2810 & 80 & 5 & $0.0031^{*}$ \\
DHCU066635 & 10.0 & 1.3 & 0.0908 & 74 & 6 & $0.0024^{*}$ \\
DHCU066634 & 9.7 & 1.2 & 0.0611 & 73 & 5 & 0.0105 \\
DHCU066604 & 9.2 & 1.2 & 0.0354 & 81 & 5 & 0.0471 \\
DHCU066615 & 8.7 & 1.2 & 0.0177 & 52 & 5 & $0.0001^{*}$ \\
DHCU066621 & 7.1 & 1.2 & $0.0016^{* y}$ & 61 & 6 & $0.0001^{*}$ \\
DHCU066600 & 6.7 & 1.3 & $0.0008^{*}$ & 51 & 6 & $0.0001^{*}$ \\
DHCU066614 & 6.7 & 1.2 & $0.0004^{*}$ & 65 & 6 & $0.0001^{*}$ \\
DHCU066616 & 4.9 & 1.3 & $0.0001^{*}$ & 45 & 5 & $0.0001^{*}$ \\
DHCU066601 & 4.5 & 1.2 & $0.0001^{*}$ & 100 & 7 & 0.6146 \\
DHCU066628 & 4.0 & 1.6 & $0.0001^{*}$ & 45 & 5 & $0.0001^{*}$ \\
DHCU066637 & 3.5 & 1.2 & $0.0001^{*}$ & & 52 & 5 \\
\hline
\end{tabular}

${ }^{\mathrm{z}}$ For row weight and for bulb weight, Bonferroni corrected alpha for 15 comparisons 0.0033 .

$\mathrm{y} *$ indicates $95 \%$ confidence of a significant difference from Festival. overrun by a tractor, noticeably lowering its stand count.

The two AmSp-type controls, Medeo and Calibra, had the lowest mean row weights at $28.5 \mathrm{~kg}$ and $22.9 \mathrm{~kg}$, respectively (Table 4). All AmSp-type DH hybrids had significantly greater mean row weight than Calibra, and five of six AmSp-type DH hybrids also had significantly greater mean row weight than Medeo. The five greatest mean row weights were the AmSp-type DH hybrids whose male parents were DHCU066619, DHCU066604, DHCU066615, DHCU066600, and DHCU066613, each of which was significantly greater for mean row weight than both Medeo and Calibra. All of the AmSptype DH hybrids were also significantly greater in mean bulb weight than Calibra, but none was significantly greater in mean bulb weight than Medeo (Table 4).

American-type hybrid trial in 2009. The results for the Am-type DH hybrids showed a highly significant difference $(P<0.0001)$ between the two locations. Mean bulb weight and mean row weight were significantly lower in the Oswego trial than in the Elba trial, indicating better growing conditions at the Elba site; therefore, the two locations were analyzed separately.

In the Am-type hybrid trial in Oswego, the half-sib commercial control Crockett had the highest mean row weight, and Safrane had a mean row weight in the center of the range (Table 5). The mean row weights for the Am-type DH hybrids with the male parents DHCU066631 were not significantly different from Crockett. Row weights of all 12 DH hybrids did not differ significantly from that of Safrane.

Mean bulb weights in the Am-type DH hybrids in Oswego varied greatly, ranging from $113 \mathrm{~g}$ to $82 \mathrm{~g}$. The majority of the DH hybrids were not significantly different for mean bulb weight than their half-sib commercial controls. However, the mean bulb weights of the DH hybrids created with DHCU066604, DHCU066631, and DHCU066630 were significantly greater than the control Safrane.

In the Elba trial of the Am-type hybrids, the two controls, Safrane and Crockett, had the lowest mean row weight at $31.4 \mathrm{~kg}$ and $28.6 \mathrm{~kg}$, respectively (Table 6). The mean row weight values for nine of the $12 \mathrm{DH}$ hybrids were significantly better than the poorer commercial control, Crockett, and three of the $12 \mathrm{DH}$ hybrids also were significantly higher for mean row weight than the better commercial control, Safrane. The hybrid created with the male lines DHCU066600, DHCU066634, and DHCU066619 had significantly higher mean bulb weight than that of the control, Crockett (Table 6).

\section{Discussion}

Doubled haploids are successfully used in commercial production of numerous crops; however, onion breeding programs have not, for the most part, used this technology. Given the biological constraint of a biennial life 
Table 4. Mean row weight and mean bulb weight of American Spanish-type (AmSp) doubled haploid hybrids compared with half-sib controls Calibra and Medeo; combined analysis of 2009 trials on commercial muck fields in Elba and Oswego.

\begin{tabular}{|c|c|c|c|c|c|c|c|c|c|}
\hline Pedigree & $\begin{array}{l}\text { No. of } \\
\text { rows }\end{array}$ & $\begin{array}{l}\text { Mean row } \\
\text { wt }(\mathrm{kg})\end{array}$ & SE & $\begin{array}{l}P \text { value different } \\
\text { from Calibra }\end{array}$ & $\begin{array}{l}P \text { value different } \\
\text { from Medeo }\end{array}$ & $\begin{array}{c}\text { Mean bulb } \\
\text { wt (g) }\end{array}$ & SE & $\begin{array}{l}P \text { value different } \\
\text { from Calibra }\end{array}$ & $\begin{array}{l}P \text { value different } \\
\text { from Medeo }\end{array}$ \\
\hline $\mathrm{AmSp}^{\mathrm{x}} \times$ DHCU066619 & 7 & 40.3 & 1.6 & $0.0000^{* z, y}$ & $0.0000^{*}$ & 124 & 5 & $0.0000^{*}$ & 0.1299 \\
\hline $\mathrm{AmSp} \times \mathrm{DHCU} 066604$ & 6 & 39.3 & 1.6 & $0.0000 *$ & $0.0000 *$ & 125 & 3 & $0.0000^{*}$ & 0.1088 \\
\hline $\mathrm{AmSp} \times \mathrm{DHCU} 066600$ & 7 & 37.0 & 1.9 & $0.0000 *$ & $0.0043 *$ & 118 & 12 & $0.0001 *$ & 0.9483 \\
\hline $\mathrm{AmSp} \times \mathrm{DHCU} 066613$ & 7 & 37.0 & 1.7 & $0.0000 *$ & $0.0004 *$ & 114 & 5 & $0.0000 *$ & 0.9792 \\
\hline $\mathrm{AmSp} \times \mathrm{DHCU} 066615$ & 7 & 36.8 & 2.3 & $0.0000 *$ & $0.0008 *$ & 113 & 4 & $0.0001 *$ & 0.9721 \\
\hline $\mathrm{AmSp} \times \mathrm{DHCU} 066601$ & 7 & 33.3 & 1.7 & $0.0000 *$ & 0.0261 & 110 & 6 & $0.0002 *$ & 0.4923 \\
\hline Medeo (AmSp-derived) & 7 & 28.5 & 1.7 & & & 115 & 3 & & \\
\hline Calibra (AmSp-derived) & 7 & 22.9 & 1.9 & & & 84 & 4 & & \\
\hline
\end{tabular}

${ }^{\mathrm{z}}$ Bonferroni corrected alpha for six comparisons 0.0083 .

$\mathrm{y} *$ indicates $95 \%$ confidence of a significant difference from the controls.

${ }^{\mathrm{x}} \mathrm{AmSp}$ is the male-sterile line that is the female parent of these experimental hybrids and of the commercial controls, Medeo and Calibra.

Table 5. Mean row weight and mean bulb weight of American-type (Am) hybrids compared with half-sib controls Safrane and Crockett in a commercial muck field in Oswego, NY, 2009.

\begin{tabular}{|c|c|c|c|c|c|c|c|c|c|}
\hline Pedigree & $\begin{array}{l}\text { No. of } \\
\text { rows }\end{array}$ & $\begin{array}{c}\text { Mean row } \\
\text { wt (kg) }\end{array}$ & SE & $\begin{array}{l}P \text { value different } \\
\text { from Safrane }\end{array}$ & $\begin{array}{l}P \text { value different } \\
\text { from Crockett }\end{array}$ & $\begin{array}{c}\text { Mean bulb } \\
\text { wt (g) }\end{array}$ & SE & $\begin{array}{l}P \text { value different } \\
\text { from Safrane }\end{array}$ & $\begin{array}{l}P \text { value different } \\
\text { from Crockett }\end{array}$ \\
\hline Crockett $\left(\right.$ Am-derived $\left.{ }^{\mathrm{x}}\right)$ & 4 & 30.0 & 0.7 & & & 111 & 1.7 & & \\
\hline Am $\times$ DHCU066631 & 4 & 27.9 & 1.7 & $0.0147^{z}$ & 0.2026 & 112 & 2.7 & $0.0000 *$ & 0.9902 \\
\hline $\mathrm{Am} \times \mathrm{DHCU} 066604$ & 4 & 25.3 & 1.7 & 0.5355 & $0.0041 * y$ & 113 & 6.5 & $0.0001 *$ & 0.7375 \\
\hline Am $\times$ DHCU066615 & 4 & 25.0 & 0.9 & 0.2429 & $0.0016^{*}$ & 98 & 4.5 & 0.0211 & 0.0314 \\
\hline Am $\times$ DHCU066613 & 4 & 25.0 & 0.2 & 0.4404 & $0.0040 *$ & 88 & 0.9 & 0.7288 & $0.0001 *$ \\
\hline $\mathrm{Am} \times \mathrm{DHCU} 066634$ & 4 & 24.0 & 1.4 & 0.7162 & $0.0012 *$ & 94 & 2.6 & 0.1427 & $0.0026^{*}$ \\
\hline $\mathrm{Am} \times \mathrm{DHCU} 066635$ & 4 & 23.8 & 1.2 & 0.9802 & $0.0006^{*}$ & 100 & 1.4 & 0.0262 & 0.0227 \\
\hline Safrane (Am-derived) & 4 & 23.8 & 0.6 & & & 87 & 2.8 & & \\
\hline Am $\times$ DHCU066630 & 4 & 23.7 & 0.8 & 0.9306 & $0.0006^{*}$ & 105 & 3.7 & $0.0017 *$ & 0.1795 \\
\hline Am $\times$ DHCU066619 & 4 & 23.4 & 1.4 & 0.7571 & $0.0010^{*}$ & 101 & 5.3 & 0.0074 & 0.0788 \\
\hline Am $\times$ DHCU066627 & 4 & 22.5 & 2.8 & 0.6911 & $0.0001 *$ & 96 & 8.2 & 0.0767 & 0.0060 \\
\hline Am $\times$ DHCU066601 & 4 & 22.2 & 0.8 & 0.5686 & $0.0001 *$ & 97 & 3.0 & 0.0575 & 0.0086 \\
\hline Am $\times$ DHCU066600 & 4 & 21.4 & 2.1 & 0.3906 & $0.0000 *$ & 86 & 3.8 & 0.8289 & $0.0001 *$ \\
\hline Am $\times$ DHCU066637 & 4 & 18.4 & 0.8 & 0.0134 & $0.0000 *$ & 82 & 2.4 & 0.5864 & $0.0001 *$ \\
\hline
\end{tabular}

${ }^{\mathrm{z}}$ For row weight and bulb weight, the Bonferroni corrected alpha for 12 comparisons 0.0042 .

$y *$ indicates $95 \%$ confidence of a significant difference from the controls.

${ }^{\mathrm{x}} \mathrm{Am}$ is the male-sterile line that is the female parent of these experimental hybrids and of the commercial controls, Crockett and Safrane.

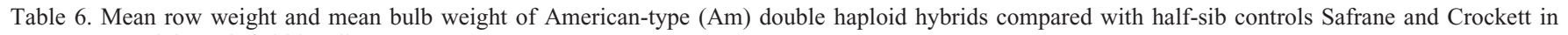
a commercial muck field in Elba, NY, 2009.

\begin{tabular}{|c|c|c|c|c|c|c|c|c|c|}
\hline Pedigree & $\begin{array}{l}\text { No. of } \\
\text { rows }\end{array}$ & $\begin{array}{l}\text { Mean row } \\
\text { wt }(\mathrm{kg})\end{array}$ & SE & $\begin{array}{l}P \text { value different } \\
\text { from Safrane }\end{array}$ & $\begin{array}{l}P \text { value different } \\
\text { from Crockett }\end{array}$ & $\begin{array}{c}\text { Mean bulb } \\
\text { wt (g) }\end{array}$ & SE & $\begin{array}{l}P \text { value different } \\
\text { from Safrane }\end{array}$ & $\begin{array}{l}P \text { value different } \\
\text { from Crockett }\end{array}$ \\
\hline$\overline{\mathrm{Am}^{\mathrm{x}} \times \mathrm{DHCU} 066619}$ & 4 & 37.5 & 0.8 & $0.0015^{* z, y}$ & $0.0000^{*}$ & 124 & 8 & 0.0084 & $0.0022 *$ \\
\hline Am $\times$ DHCU066600 & 4 & 37.4 & 1.1 & $0.0003 *$ & $0.0000 *$ & 128 & 6 & 0.0073 & $0.0017^{*}$ \\
\hline Am $\times$ DHCU066615 & 4 & 37.0 & 1.1 & $0.0032 *$ & $0.0000 *$ & 122 & 4 & 0.0195 & 0.0054 \\
\hline Am $\times$ DHCU066634 & 4 & 36.9 & 0.8 & 0.0059 & $0.0001 *$ & 125 & 6 & 0.0157 & $0.0040 *$ \\
\hline Am $\times$ DHCU066635 & 4 & 36.4 & 1.2 & 0.0070 & $0.0001^{*}$ & 115 & 4 & 0.0905 & 0.0304 \\
\hline Am $\times$ DHCU066627 & 4 & 35.6 & 3.0 & 0.0184 & $0.0003 *$ & 110 & 8 & 0.1939 & 0.0763 \\
\hline Am $\times$ DHCU066601 & 4 & 35.2 & 1.1 & 0.0392 & $0.0007 *$ & 114 & 6 & 0.1619 & 0.0583 \\
\hline Am $\times$ DHCU066604 & 4 & 35.2 & 0.9 & 0.0451 & $0.0009 *$ & 118 & 9 & 0.0734 & 0.0229 \\
\hline Am $\times$ DHCU066630 & 4 & 35.1 & 2.1 & 0.0509 & $0.0010 *$ & 116 & 7 & 0.1345 & 0.0459 \\
\hline Am $\times$ DHCU066631 & 4 & 33.4 & 1.9 & 0.2526 & 0.0101 & 101 & 6 & 0.7953 & 0.7845 \\
\hline Am $\times$ DHCU066613 & 4 & 33.4 & 1.4 & 0.4115 & 0.0223 & 117 & 7 & 0.3323 & 0.1354 \\
\hline Am $\times$ DHCU066637 & 4 & 31.6 & 1.1 & 0.6867 & 0.0671 & 100 & 3 & 0.9054 & 0.5322 \\
\hline Safrane (Am-derived) & 4 & 31.4 & 0.7 & & & 105 & 3 & & \\
\hline Crockett (Am-derived) & 4 & 28.6 & 0.1 & & & 102 & 4 & & \\
\hline
\end{tabular}

${ }^{\mathrm{z} B o n f e r r o n i}$ corrected alpha for 12 comparisons 0.0042 .

$\mathrm{y} *$ indicates $95 \%$ confidence of a significant difference from the control.

${ }^{\mathrm{x}} \mathrm{Am}$ is the male-sterile line that is the female parent of these experimental hybrids and of the commercial controls, Crockett and Safrane.

cycle, commercial onion breeding should greatly benefit from reduced production time by using DH inbred lines as parents of hybrid varieties. Our study shows that DHs can be used as onion inbred lines with as high or higher levels of vigor than traditionally bred inbred lines. This agrees with prior observation of DH lines of other crops such as maize, rice, wheat, and Brassica vegetables, which exhibit a relatively high level of vegetative vigor compared with traditional inbred lines, although they are entirely homozygous
(Bohanec, 2002; Bong and Swaminathan, 1995; Kim et al., 2007). The onion DH lines produced also show exceptional combining ability, vigor, and potential yield.

Most of the DH onion lines in our trials in 2006 and 2008 showed a similar pattern of performance as reported for other crops (Bohanec, 2002; Bong and Swaminathan, 1995; Maluszynski et al., 2003). The DH onion lines were comparable in mean row weight and mean bulb weight to their openpollinated sources and were only slightly lower for these traits than the commercial onion hybrid controls (Tables 2 and 3). DH lines of rice, maize, and onion also did not reach the same level of vigor as that found in hybrids (Bong and Swaminathan, 1995; Kim et al., 2007; Röber et al., 2005). The striking vigor in these $\mathrm{DH}$ onion lines might be the result of a lack of deleterious or sublethal alleles. During the first stages of gynogenesis, the DH plantlets are completely haploid with no dominance masking deleterious alleles. Genes that are strongly deleterious to vegetative 
growth and development would kill the plantlets containing them in vitro during development. This would result in recovery of fewer DH plants but also a tendency for the $\mathrm{DH}$ plants produced to be free of the most deleterious alleles. In the production of these $\mathrm{DH}$ onion lines, culture of 47,000 onion flowers led to recovery of 1,100 gynogenic plants (Alan et al., 2003, 2004). This low recovery rate, similar to other work on onion DH lines (Bohanec, 2002; Kim et al., 2007), could reflect a high level of in vitro selection, which could in turn result in the superior vigor of some of the $\mathrm{DH}$ lines recovered. This suggests that high levels of vigor can be attained by removing deleterious genes. Alternatively, it has recently been suggested that inbreeding depression involves increasing levels of DNA methylation during repeated cycles of self-pollination (Pennisi, 2011). It is possible that the production of DH lines through gynogenesis results in reduced methylation, allowing $\mathrm{DH}$ lines to avoid inbreeding depression.

If removal of deleterious alleles or lack of methylation in creation of DH lines does increase vegetative vigor, DH lines should be ideal for use as parents of hybrids. Such DH lines would be expected to show considerable broad-sense combining ability, the capability to produce hybrids with superior vegetative growth while crossing onto diverse female lines. Therefore, DH lines are uniquely suited for use in commercial hybrid combinations.

Our results show that many of the onion hybrids created with DH lines as male parents can have greater vigor, as assessed by mean row weight and mean bulb weight, than their half-sib commercial hybrid controls. More than half of the nine AmSp-type hybrids in 2008 were greater for mean row weight and mean bulb weight than both hybrid controls with female line in common, and all six in the 2009 trial were greater than both controls with only one not being significant (Table 4). The Am-type hybrids in 2008 performed comparably to the controls; however, no significant differences were detected as a result of exceptionally variable field conditions. In the Oswego 2009 trial, under less favorable conditions, the DH hybrids performed comparably to the control hybrids in vegetative vigor (Table 5). Under the more favorable conditions of the Elba 2009 trial, both mean row weight and mean bulb weight were higher for all the DH hybrid lines, many being significantly higher (Table 6). Given that experimental hybrids and control hybrids in each set (Am and AmSp) share the same females, the differences in performance within the two sets of half-sib hybrids are attributable to differences in the male parent.

Many traits beyond the vigor that affects yield and bulb size must be considered in determining the potential of an onion hybrid. Although the in vitro selection inherent in DH production might be beneficial for yield, it would not eliminate all deleterious alleles. Traits governed by genes that are not expressed during gynogenesis and/or did not affect the success and early development or vegetative growth of the DH plantlets would be unlikely to be affected by in vitro selection. For example, genes controlling bulb color, glossy leaf, bulb shape, skin characteristics, or many other important horticultural traits would probably not be subject to selection in the creation of DH plantlets.

Because the DH lines were independently derived, there were differences among $\mathrm{DH}$ lines, and among their hybrids, for various characteristics. Although a replicated analysis of bulb traits such as neck thickness, skin tightness, skin color, etc., were not performed for each of the trials, observation of bulbs during grading showed no striking differences between the DH hybrids and the conventional hybrids for such traits, that is, the bulb characteristics of the DH hybrids were generally as acceptable as the commercial hybrid controls. However, there was a strong trend for greater uniformity of bulb shape within most of the DH hybrids than in the commercial controls.

DH lines are completely homozygous; therefore, genetically controlled traits such as shape, maturity, leaf wax, plant structure, number of centers, pungency, disease resistance, and soluble solid content would be more uniform in hybrids created with $\mathrm{DH}$ parents. However, fixation of some traits in $\mathrm{DH}$ lines, and their uniformity in DH hybrids, could also result in poorer quality if the trait was fixed for the unfavorable allele for a character, resulting in undesirable bulb shape, color, neck thickness, or any other characteristic unlikely to be affected by the selection pressure inherent in the process of generating DH lines. A DH line possessing undesirable traits cannot be improved through selection and must be discarded.

Aside from the increased vigor and homozygosity possible in DH lines and hybrids, the use of DH lines is beneficial to breeding programs as a result of the rapid time and lower costs incurred to generate DH inbred lines compared with conventionally bred inbred lines. Therefore, DH lines are increasingly being used in crops such as rice and maize, rapeseed, tobacco, and barley (Bohanec, 2002; Bong and Swaminathan, 1995; Maluszynski et al., 2003; Röber et al., 2005). This use is considered a major advance in maize breeding and genetics (Röber et al., 2005). Savings exist because of the reduced costs of sub-line production and evaluation costs of lines as they are developed. Once a DH line is produced, it is a fully homozygous finished product, and no additional selection is needed to further refine the line. Generation time is short; therefore, lines can be fixed for gene combinations in the shortest amount of time with the lowest genotyping expense. Once lines are produced, no maintenance selection is needed as long as pollination is strictly controlled to maintain the purity of the DH lines. Furthermore, as a result of their absolute uniformity and homozygosity, it is easy for DH lines to meet the needs for protection under plant variety rights. Onion breeding can benefit from using DHs in the same manner, especially with regard to generation time, because onions are a biennial crop with a two-year life cycle.

The ability of current methods to create DH onion lines efficiently is clear. In some onion sources such as SYN-YIX E, doubled haploids were recovered at $\approx 5 \%$ (Alan et al., 2004), a frequency rate comparable to that commonly used in maize (Röber et al., 2005). It is possible that the high level of heterozygosity of the onion sources SYN-YIX E and SYN-YIX C used to generate the DH lines was one reason for the relatively high rate of recovery of DH lines from these sources. Creation of DH lines without deleterious genes is more likely if heterozygous materials are used as starting material rather than conventional inbred lines that would probably already be homozygous for some deleterious genes as reflected in their degree of inbreeding depression. Therefore, efforts to produce vigorous onion DH lines could benefit from maximizing the heterozygosity of their starting plant materials rather than attempting to improve inbred lines already suffering from inbreeding depression.

The fact that so many of the DH hybrids tested were superior for mean row weight and mean bulb weight creates a pool of experimental hybrids to allow further selection of those hybrids with the preferred quality characteristics. The DH line CUDH066631 performed better than all others both in tests as a line (Tables 2 and 3 ) and as a parent of American-type hybrids (Table 5). However, these hybrid tests were limited to hybrids created with only two female parents, and it is possible that other DH lines could be parents of equally superior hybrids when crossed onto different female lines. Therefore, expanding testing of DH-derived hybrids using additional females would be desirable. The increased uniformity, reduction in production and maintenance costs, increased speed of production, and increased yields of $\mathrm{DH}$ hybrids warrant the use of $\mathrm{DH}$ lines in the development of new onion hybrids. The $\mathrm{DH}$ onion lines included in this work have been released by the Cornell onion breeding program.

\section{Literature Cited}

Alan, A.R., A. Brants, E. Cobb, P. Goldschmied, M.A. Mutschler, and E.D. Earle. 2004. Fecund gynogenic lines from onion (Allium cepa $\mathrm{L}$.) breeding materials. Plant Sci. 167:1055-1066.

Alan, A.R., M.A. Mutschler, A. Brants, E. Cobb, and E.D. Earle. 2003. Production of gynogenic plants from hybrids of Allium cepa L. and A. roylei Stearn. Plant Sci. 165:1201-1211.

Bohanec, B. 2002. Doubled haploid onions, p. 145158 In: Rabinowitch, H.D. and L. Currah (eds.). Allium crop science: Recent advances. CABI Publishing, Wallingford, UK.

Bong, B.B. and M.S. Swaminathan. 1995. Magnitude of hybrid vigor retained in double haploid lines of some heterotic rice hybrids. Theor. Appl. Genet. 90:253-257.

Boodley, J.W. and R. Sheldrake. 1972. Cornell peat-lite mixes for commercial plant growing. Cornell University Cooperative Extension Division Informational Bulletin 43.3. 
Dowker, D. and G.H. Gordon. 1983. Heterosis and hybrid cultivars in onions, p. 220-231. In: Frankel, R. (ed.) Heterosis. Monographs on Theoretical and Applied Genetics. SpringerVerlag.

Evoor, S., R. Veere Gowda, E. Gangappa, and R. Krisna Monohar. 2007. Heterosis for yield, yield components and quality traits in onion (Allium cepa L.). Karnataka Journal of Agricultural Science 20:813-815.

Hosfield, G.L., G. Vest, and C.E. Peterson. 1977. Heterosis and combining ability in a diallel cross of onions. J. Amer. Soc. Hort. Sci. 102: 355-360.
Jones, H.A. and A. Clarke. 1943. Inheritance of male sterility in the onion and the production of hybrid seed. Proceedings American Society of Horticultural Science 43 : 189-194.

Jones, H.A. and G. Davis. 1944. Inbreeding and heterosis and their relation to the development of new varieties of onions. USDA Technical Bulletin 874.

Joshi, H. and J. Tandon. 1976. Heterosis for yield and its genetic basis in the onion. Indian Journal of Agricultural Science 46:88-92.

Kim, S., K.S. Yoo, and L.M. Pike. 2007. Production of doubled haploid onions (Allium сера) and evaluation of their field performance. Horticulture Environment, and Biotechnology 48:143-147.

Maluszynski, M., K.J. Kasha, B.P. Forster, and I. Szarejko. 2003. Doubled haploid production in crop plants: A manual. Kluwer Academic Publ., Boston, MA.

Pennisi, E. 2011. Epigenetics linked to inbreeding depression. Science 333:1563.

Röber, F., G.A. Gordillo, and H.H. Geiger. 2005. In vivo haploid induction in maize-Performance of new inducers and significance of doubled haploid lines in hybrid breeding. Maydica 50: 275-283. 